In his epilogue, Dyson ruminates on the ascendancy of machines in our lives. A watershed for him was the defeat of Gary Kasparov by the chess-playing computer, Deep Blue, in 1997, a profoundly dispiriting event for many of us. Inevitable, says Dyson, and, of course, viewed as art succumbing to brute megabytes, tragic. But even here Dyson sees the promise of something greater to come, of art combining with machine to produce a new and deeper beauty. Let us hope so.

So, as the Reverend Sydney Smith observed during a time of trial, "cheerfulness will keep breaking through". "The game of evolution", Dyson assures us in his peroration, "will in future be played by humans and machines playing together. The landscape of cyberspace offers us as much scope for artistic creation as the landscape of a chessboard."

You may not be entirely persuaded by these assurances, but you will certainly feel the better for a bracing hour or two in Freeman Dyson's company.

Walter Gratzer is at the Randall Institute,

King's College, 26-29 Drury Lane,

London WC2B 5RL, UK.

\section{Turning evening into morning}

\section{Time of our Lives}

by Tom Kirkwood

Weidenfeld \& Nicolson: 1998. 287 pp. $£ 20$

\section{John Bayley}

It's a grand life if you don't weaken, as they used to say. Or if you don't get anything wrong with you. In the old days you almost invariably did. TB, cancer, hypertension, pneumonia above all - they could carry you off without much fuss or bother between the fifth and seventh decades of life. But now, says Tom Kirkwood, we ought to become more conscious of the fact that those once almost inevitable shorteners of our lives don't come round for us any more. We should draw a deep breath and make the most of what used to be the evening of our lives. Make it a new morning.

Kirkwood's hearty tone and vigorous mode of exposition are agreeable to nonscientists, even if they do not necessarily grasp all the implications of a scientific argument. Take the little matter of cell ageing, on which much of the general optimism of Kirkwood's thesis depends. He tells the story of the conceited though charismatic French surgeon Alexis Carrel, a Nobel prizewinner who demonstrated that cells outside the body could be kept alive indefinitely in a properly maintained culture, and continue to grow. This seemed good news until Paul Moorhead and Leonard Hayflick demonstrated in their turn that actual body cells appear to be subject to what became known

as the Hayflick limit, the point beyond which cell reduplication did not continue. Could this be because cell ageing and final extinction are programmed as part of the ageing process? In other words, even if we escape the more obvious maladies of mortality, will we die just because our cells give up?

To help lay readers grasp the point, Kirkwood takes the analogy of an airliner hurtling down the runway towards take-off. Should something be still at fault after the elaborate pre-flight checks, a red light will come on in the cockpit, the crew will be alert-

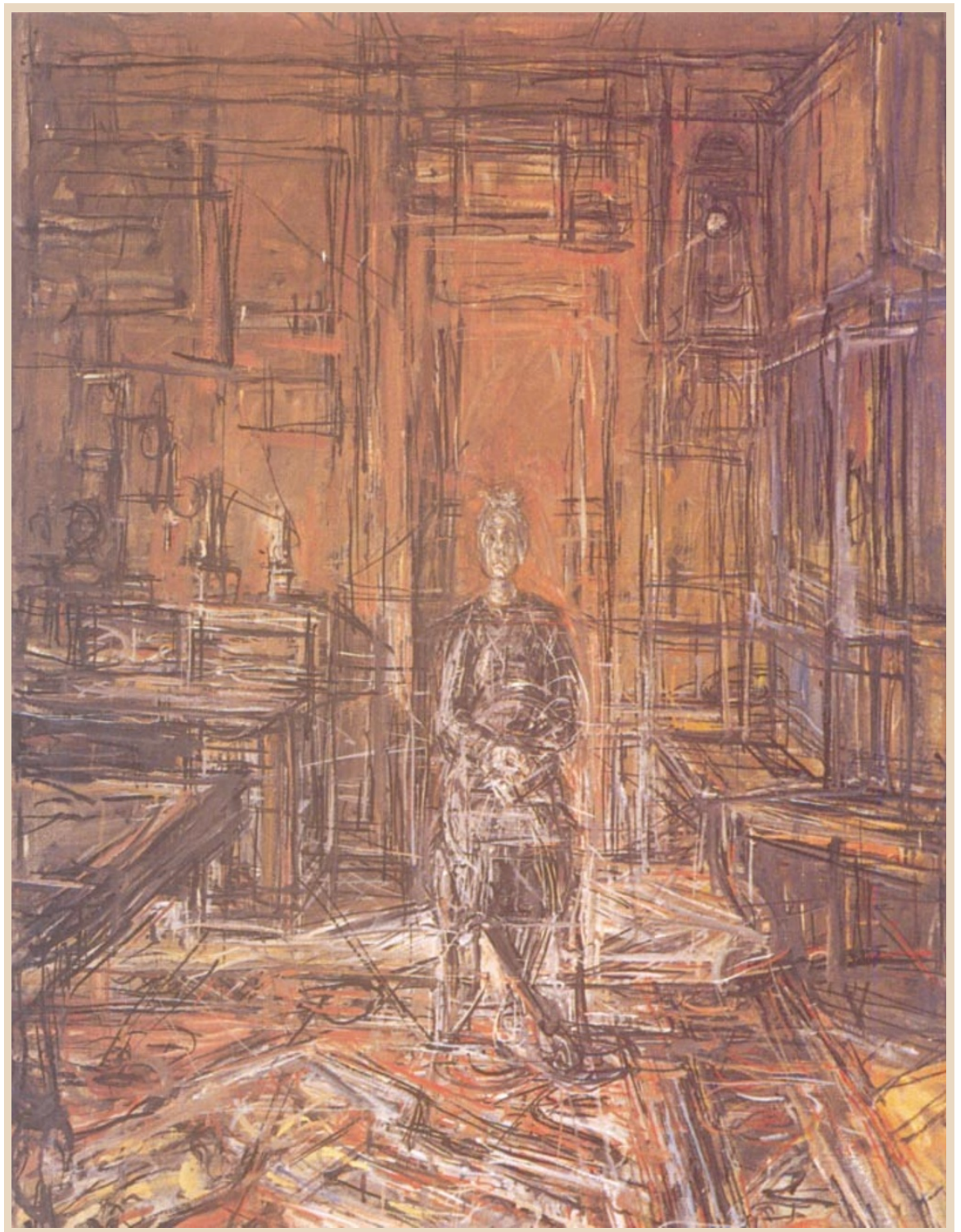

\title{
Mind where you put your molecules
}

Although Memory: From Mind to Molecules by Larry Squire and Eric Kandel is 69th in the Scientific American Library series (\$34.95, $£ 23.95$ ), it is highly individual. The book is a deftly crafted tour of the study of memory from a brief history of the science, via synapses and neurophysiology, to psychology and what the authors refer to as "the biological basis of individuality". And all this in ten short chapters. ed and the flight aborted. But a wholly clueless outsider might draw the conclusion that the red light was itself the cause of the problem. Cell ageing, that is to say, may not be programmed, but may be the result of random damage or accident over a cumulative period, which will finally have the result of the whole immensely complex system packing up.

I am not convinced that this argument is particularly good news for septuagenarians who may be hoping to enjoy the time of their lives. What may be good news scientifically is
As ever, Kandel and Squire write superbly even for the vaguely interested non-specialist. To crown it all, each chapter is fronted by a modern painting, the relevance of which is valiantly argued by the caption. Alberto Giacometti worked in cycles, creating from memory and then destroying successive works to produce a final version, such as "The artist's mother" (1950) shown here and fronting chapter 10. 
perhaps best forgotten by those who are toiling on from day to day, and getting by as best they can. Causation, or its opposite, is itself an unsettling matter for the unscientific mind. Which would you rather feel: that your cancer has been genetically programmed, induced by stress or caused by viruses? Brought about by your own folly in smoking cigarettes, or - as Kirkwood himself appears to take for granted - brought about casually and spontaneously through the operation of chance? If it is put before them in this way, most people would rather not think about the matter at all.

Kirkwood - who is professor of gerontology at Manchester University - takes a different view, maintaining that the more we know about the ageing process the more we can "exercise a greater degree of personal control". Common sense certainly tells us oldies to take it easy, to cut down a bit on food and alcohol and strenuous exercise, but we know this from the feel of our bodies rather than from what we read about the progress of science.

To declare an interest of my own, my wife, Iris Murdoch, died recently. For four years she had been suffering from Alzheimer's disease, a brain disorder. Research was trying to find out why people died apparently not of, but with, this disease: what were the factors involved that produced a life-threatening situation? Apart from her mental troubles my wife had seemed to be in good health, eating and functioning normally. In a sense she seemed young rather than old, and I fed her, washed and cared for her as one would a three-year-old child. She seemed herself to attempt to adapt to this situation, to become good at it, just as she herself had been a good

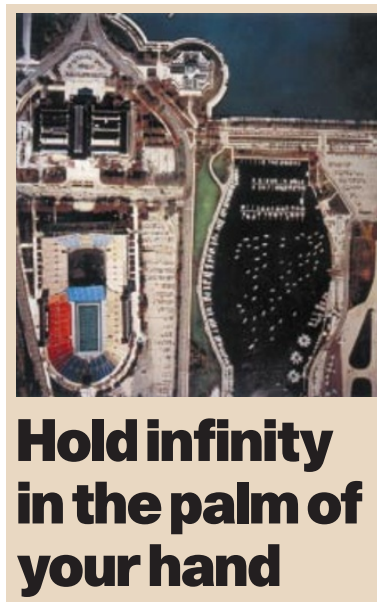

A change in magnification of $10^{38}$ will take you from beyond the Galaxy into the nucleus of a carbon atom - a zoom that any film maker would envy.
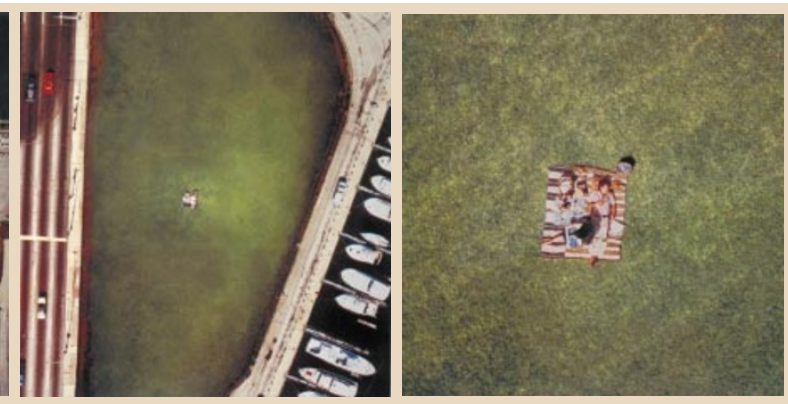

Powers of Ten (Freeman, \$9.95) makes this journey in a 'flipbook' based on a short film by Charles and Ray Eames, better known as the designers of some of the century's most famous furniture. These pictures on the human scale

person, as well as a great novelist and writer.

But quite suddenly, and as if more brain cells had switched off their circuitry, she stopped eating and drinking. My impression was that she wanted to be good at this too, as if swiftly to produce its best result. She died peacefully and quietly in my arms, and the medical certificate gave the cause as broncho-pneumonia. The doctor told me, between ourselves, that there was no sign of this, but one could hardly write down "starvation and dehydration".

The function of consciousness in this ending remained mysterious, at least to me. One could hardly feel that Iris had retained any capacity "to exercise a degree of personal control". But her body seemed to know what it wanted, and how to set about getting it. No doubt an illusion of the outsider, like the red light in the cockpit being the cause of the trouble, but it was strangely comforting to feel that in this most helpless and hopeless of disorders the body was not just dependent for its decisions on cellular malfunction or termination.

One of the charms of Kirkwood's book is the vitality and insight conferred by its humour (humour that also survived in a 79year-old woman transformed back into a three-year-old child). The best thing about growing old might be to have a good chuckle at it. As W. C. Fields, a lifelong hater of temperance-obsessed Philadelphia, did when he decided to make them write on his gravestone: "On the whole I'd rather be in Philadelphia". That is one of the jokes Kirkwood tells in the course of an immensely shrewd but also light-hearted survey of our current prospects and situation, agewise:

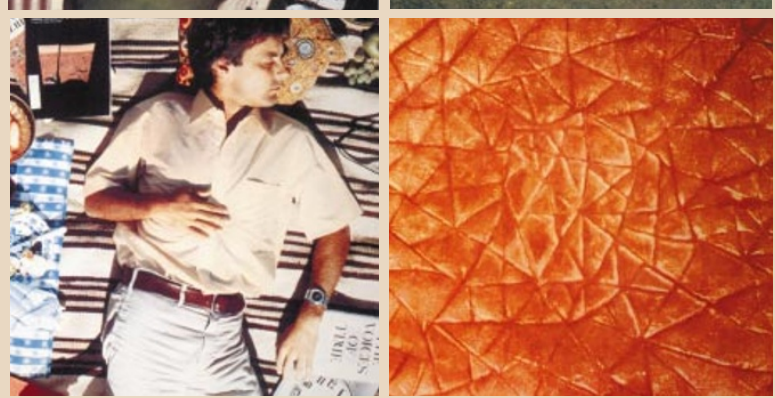

make up the film's pivotal central sequence, as we swoop down on, and into, the hand of an unsuspecting Chicago picnicker, rendered unconscious by his heavy lunch and even heavier choice of scientific reading matter. and, as he more controversially maintains, what we ourselves ought to know and to do about it.

I feel sure he would agree with what might be termed the law of conservation of trouble. If we do live longer, remain more healthy and more alert, the young, for one thing, are not going to like it at all. They would much rather look after us than have to compete with us Kirkwood, who evidently knows Africa well, has some pertinent concluding remarks on the current grave difficulties in tribal societies where the authority of the old, once questioned, is today not so much challenged as ignored. To the young there who want to live and work in go-ahead towns, the old have become irrelevant. It would be an irony if we could all start to expect to live to 100 , and yet have to be sensibly programmed in some future social and scientific Utopia to die at 60 .

One of Kirkwood's engaging habits in this book is to preface his chapters with some suitable quotation from wise old poetry. (However young poets may die, poetry always knows how to grow old gracefully.) He omits, however, the ending of the Swinburne lyric, which thanks "whatever gods maybe",

\section{That no man lives for ever}

That dead men rise up never

That even the weariest river

Winds somewhere safe to sea.

John Bayley is at St Catherine's College, Oxford OX1 3UJ, UK.

\section{Sans hair, sans teeth ...}

A Means to an End: The Biological Basis of Aging and Death

by William R. Clark

Oxford University Press, £18.99, \$27.50

For those who want more of the same medicine, this immunologist and experienced popularscience writer's latest book is on ageing. And he covers mostly the same scientific ground as Kirkwood in a similar way.

\section{Molecular Biology of Aging}

edited by Vilhelm A. Bohr, Brian F. C. Clark \&

Tinna Stevnsner

Munksgaard, DKr400

For the specialist, the edited papers presented at the 44th Alfred Benzon symposium held in Copenhagen in June 1998.

\section{How and Why We Age}

by Leonard Hayflick

Ballantine, \$14, £8.99

"Many a scientist has found immortality but none by Woody Allen's preferred method — not dying. Avogadro lives on through his number, Planck his constant, Ohm his law. Leonard Hayflick, happily very much alive today, will be known to future generations for discovering the Hayflick limit, a phenomenon that seems partly responsible for the certainty that Woody Allen's wish is one day going to be thwarted ... Written 
in clear, nontechnical language, [Hayflick's book] is an excellent introduction to the scientific and demographic literature on this multifaceted subject." Tom Kirkwood, Nature 373, 484-485 (1995)

\section{Lord of \\ the flies}

\section{Time, Love, and Memory: A Great Biologist and His Quest for the Origins of Behavior}

by Jonathan Weiner

Alfred A. Knopf: 1999. 290 pp. \$27

\section{Yadin Dudai}

William of Occam preached that "entities should not be multiplied beyond necessity", but did not forget to add: "there are many things that God does with more that he could do with fewer." The interplay between bold and cautious Occamism is the secret of successful science. This book is about a scientist who for the past six decades has navigated his way in a marvellously idiosyncratic style on the edge of Occam's razor, and swept biology, once and again, into new territories.

In the 1950s, in his adventures into the genetics of a virus, Seymour Benzer tore a window to the microcosm of the gene. In the late 1960s, toying with fruitflies in test-tubes, he altered neurobiology. Hundreds of hectic investigators at this very moment run knockout mice in watermazes, slice the brains of transgenics or compose a paper to convince the world that their

\section{Dance at sea}

Many seahorses form faithful longterm pair bonds which are reinforced by greeting rituals. The male and female may swim towards each other and dance together before changing colour and mating. The female plants sticky strings of eggs in the male's pouch, and he broods the embryos for up to six weeks before going into labour to produce fully independent young. It is no wonder that these bizarre creatures have fascinated people since at least the time of the ancient Greeks. The first guidebook to the world's seahorses does justice to their beauty and extraordinary biology, while being a userfriendly identification handbook and offering practical advice on the urgent need for conservation. Seahorses: An Identification Guide to the World's Species and their Conservation is by Sara A. Lourie, Amanda C. J. Vincent and Heather J. Hall (publisher, Project Seahorse, $\mathfrak{E} 19.95, \mathbf{3 2 . 9 5}$; distributed by NHBS; e-mail:nhbs@nhbs.co.uk).

\section{,}

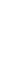

mutant is the only clue to dementia. Many of them may not even have the faintest idea how it all started. Such is the fate of success: E. O. Wilson, cited by Jonathan Weiner, commented: "progress in a scientific discipline can be measured by how quickly its founders are forgotten." Time, Love, and Memory may hence be prescribed as an anti-amnesic potion to generations of neuroscientists.

Weiner's book is about Benzer and his quest for the origins of behaviour; it is also about a fascinating chapter in the history of science that, because the investigator and his organism played it low-key, was protected from attention for far too long — including probably the attention of the jury in Stockholm.

Benzer's lab at its most intensive period was off-off-Broadway, but it is there that a dominant scientific culture was founded. Time, Love, and Memory navigates us through Benzer's career with great detail, encompassing both scientific and personal life. We learn about the early days in physics (Benzer was among the discoverers of transistor technology); about the fascination with Erwin Schrödinger's What is Life?; and about the influence of another physicist, Max Delbrück, who started modern molecular biology by focusing on the tiny viruses — bacteriophage — as atoms of inheritance.

Benzer was drafted into the reductionist revolution. After years of almost manic research, he was able to present the world

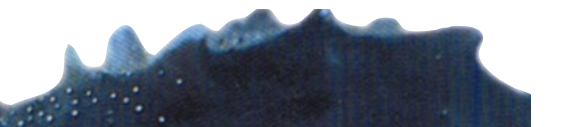

with the first fine physical map of a gene. This turned him into the legendary 'atom-breaker of biology'. Other scientists would have probably capitalized on the success past retirement well into afterlife. Not Benzer. A loner by nature (a mutant?), Benzer consistently shies away from the crowds, especially when they attempt to join him. He is a scout, not a general, an obsessive wanderer into uncharted terrain.

Indeed, for a while he drifted into the more tranquil waters of RNA research. Delbrück, who started getting reprints, was quick to react: "Please ask Seymour," he wrote to Benzer's first wife, Dotty, "to stop writing so many papers... If he must continue, tell him to do what Ernst Mayer asked his mother to do in her long daily letters, namely, underline what is important." Benzer learned a lesson that should be included in the curriculum of every biology programme: 'beware of falling into the biochemical drain'.

He traded phage for fruitflies. The rest is history. In 1967 he published his first neurogenetic paper: "Behavioural mutants of Drosophila isolated by countercurrent distribution". It is the epitome of an ingeniously simple approach to an extremely complex problem. The basic idea behind it all is: treat flies as atoms of behaviour. Induce single gene mutations. Devise a simple behavioural assay. Isolate mutants that flunk in the test. You now have an entry point into the dissection of behaviour.

Over the years, hundreds of mutants were identified. Weiner concentrates on three classes: clock mutants, which disrupt biological rhythms; love mutants, which disrupt courtship; and memory mutants. Nowadays, mainstream neuroscience mutates mice. Because scientists hate to learn from experience, in its infancy mouse neurogenetics fell into some of the pitfalls that Drosophila neurogenetics escaped from long ago, such as artefacts caused by genetic background, pleiotropism and hidden developmental lesions.

Weiner's book is well written and fun to read, although the question arises, who is the audience? This is scientific reportage and as such should not be expected to provide indepth analysis of tenets and conclusions. Therefore, those who wish to find a critical assessment of neurogenetics should look elsewhere.

Many questions do deserve serious consideration. For example, what is the price of over-simplification? And what do genes tell us about behaviour? Consider, for example, the remarkable memory mutants. Those isolated so far affect the nuts-and-bolts of cellular plasticity. They are therefore 'plasticity mutants'. Memories are experience-dependent internal representations whose analysis must involve circuit and system levels. The expectation that neurogenetics per se would explain 'memory' thus neglects levels of 